\title{
Um ensaio sobre o adequado tratamento ao ato cooperativo de consumo
}

\author{
Guilherme Krueger ${ }^{1}$
}

Sumario: Introdução. I. O ato cooperativo de consumo. II. A defesa do consumidor. III. A assimetria nas cooperativas. IV. A transcendentalidade da relação da cooperativa com o seu sócio consumidor para sua adequada defesa. V. A constituição de um adequado tratamento ao ato cooperativo de consumo.

Resumo: No recorte temático do presente ensaio, interessa dar sentido à existência jurídica da cooperativa de consumo, eletrificação, ou habitacional na sua manifestação originária e isso passa por sua coexistência na ordem econômica, seja em relação às empresas concorrentes ou fornecedoras, seja em relação aos seus sócios.

Palavras-chave: ato cooperativo, defensa do consumidor.

Abstract: This essay focuses on explaining the meaning of the legal existence of consumer, electrification or housing cooperatives in their original form. This necessarily involves economic coexistence, whether with competitors or suppliers or in the relationship with members.

Key words: cooperative act; consumer protection.

1 Secretário da Comissão Especial de Direito Cooperativo da Ordem dos Advogados do Brasil-Seção do Estado do Rio de Janeiro. 


\section{Introdução}

Sempre que a magistratura brasileira aplica o Código de Defesa do Consumidor a uma relação de consumo havida entre uma cooperativa de consumo, eletrificação ou habitacional e um sócio seu em litígio com ela por sua insatisfação no proveito da atividade econômica que constitui o objeto da cooperativa, transpassa aos cooperativistas um sentimento de injustiça e de incompreensão pelo juiz do fenômeno da cooperação, ou de insensibilidade para com a natureza jurídica própria das cooperativas e a relação societária havida entre as partes em litígio.

É que há por parte do cooperativista uma pré-compreensão intuída da sua vivência da cooperação numa atividade econômica e formada pelo que ele sabe da já sesquicentenária doutrina cooperativista. Esta pré-compreensão da matéria jurídica evidencia uma grande diferença entre um ato cooperativo de consumo e o negócio jurídico que estabelece uma relação de mercado que tenha por objeto bens de consumo.

Essa pré-compreensão induz até mesmo a uma pretensão de se negar a condição de consumidor ao sócio de uma cooperativa. O que gera uma situação no mínimo curiosa de se admitir a existência de cooperativas de consumo... sem consumidores. Bem, há que se ponderar que a pretensão se refere ao que o Código de Defesa do Consumidor conceitua como consumidor. Mas aí a irracionalidade se manifesta ao se admitir implícitamente a possibilidade de se formular conceitos jurídicos auto-fundantes, quando é certo que um conceito jurídico positivado, como é o caso do consumidor, só se justifica, quando concretiza um sentido aceitável de coexistência vivida no mundo. A vivência no mundo indica que a cooperação não desnatura o consumo, como o consumo não é incompatível com a cooperação.

Fica patente a necessidade de uma atitude transcendental para se dar um sentido à relação de consumo estabelecida a partir de um acordo de vontades orientada à cooperação na ordem econômica constitucionalizada, que revele um ideal de justiça consubstanciado num adequado tratamento ao ato cooperativo de consumo. Em outras palavras, no recorte temático do presente ensaio, interessa dar sentido à existência jurídica da cooperativa de consumo, eletrificação, ou habitacional na sua manifestação originária e isso passa por sua coexistência na ordem econômica, seja em relação às empresas concorrentes ou fornecedoras, seja em relação aos seus sócios.

Tanto o magistrado que aplica o CDC nos litígios entre os sócios e suas cooperativas de consumo, eletrificação e habitacionais, como o cooperativista que se sente injustiçado com essa aplicação, convido 
a uma epoché ${ }^{2}$ ou seja, à uma suspensão provisória das respectivas crenças de vigência da dogmática jurídica para examinar o consumo pelo modo cooperativo, em carne-e-osso. A partir daí, poder-se-á transcender o conflito entre as diferentes noções de justiça que hoje deixam inconciliáveis o Direito Cooperativo e o Direito Consumerista na concreção das normas vigentes face aos litígios envolvendo relações de consumo entre cooperativas e seus sócios e então viabilizar a constituição de um adequado tratamento ao ato cooperativo de consumo.

\section{O ato cooperativo de consumo}

O que singulariza todo o ato cooperativo, em contraste com os atos de mercado ? Entre o sócio e a cooperativa, este sempre um fornecedor ou recebedor de bens ou serviços para aquele ou daquele, não há oposição de interesses de conteúdo econômico transacional. Em outras palavras, a cooperativa opera orientado para proveito direto e imediato de seu sócio, e não orientado para o proveito próprio a fim de maximizar resultados positivos a serem distribuídos aos sócios no gozo da propriedade da sociedade. Isso ocorre:

- pela renúncia parcial dos poderes de propriedade do sócio sobre a sociedade (gestão democrática, alienabilidade parcial das quotaspartes, indivisibilidade parcial do patrimônio líquido e dos resultados positivos, remuneração limitada do capital integralizado);

- pela distribuição dos resultados divisíveis, conforme as operações;

- pelo retorno integral dos resultados da atividade operacional com o sócio a ele, deduzidos exclusivamente os valores que são indivisíveis e para o custeio dos tributos, da gestão administrativa e financeira, da assistência e das próprias transações.

2 «A serviço de tal 'reflexividade radical' própria da atitude fenomenológica, a epoché proporcionará —enquanto um instrumento de depuração do fenômeno- o des/ocamento da atenção, inicialmente voltada para os fatos contingentes do mundo natural, para o domínio de uma subjetividade transcendental, dentro da qual e a partir da qual os "fenômenos" —enquanto idealidades puras - se revelarão como "evidências absolutas" para uma consciência transcendental, dotada da capacidade de ver verdadeiramente estes fenômenos tal como se apresentam em plena evidência.» Tourinho, Carlos Diógenes. A filosofia como ciência rigorosa, a crítica ao psicologismo e a auto-reflexão da consciência transcendental. Cadernos da Escola da Magistratura Regional Federal da 2. ${ }^{a}$ Região: fenomenologia e direito / Escola da Magistratura Regional Federal, Tribunal Regional Federal da 2. ${ }^{a}$ Região, vol. 3, n. 2 (out. 2010/mar. 2011). Rio de Janeiro: TRF 2. ${ }^{a}$ Região, 2008, v, pp. 120-121. 
Enfim, pelas características do sistema operacional que identificam universalmente uma cooperativa como tal, não faz sentido que a cooperativa logre vantagens patrimoniais para si, porque se manifestaria uma alienação do próprio sócio, como usuário da sociedade, com fins de distribuição do resultado dessa alienação ao sócio, como dono da sociedade.

Nota-se que o ato é cooperativo independentemente de seu objeto. É cooperativo pelo sentido como se relacionam as partes, em termos da sistemática de seus direitos e obrigações. Por isso, a cooperativa pode ter por objeto qualquer operação, bem ou serviços. Inclusive os bens de consumo, ou a eles equiparáveis para fins de direito.

Outrossim, há que se ter claro que o ato cooperativo é, antes de mais nada, ato jurídico. Mais precisamente, um negócio jurídico que cria, altera, mantém ou extingue direitos e obrigações recíprocas. Portanto, o ato cooperativo é uma manifestação da vontade concordante da cooperativa e seu sócio. Ela, veja-se muito bem, não se confunde com o fato jurídico que decorre da manifestação da vontade, ou seja, a relação que se estabelece ou se estabeleceu.

Enfim, o ato cooperativo então manifesta uma intenção dos sujeitos que o pratica, ou seja, a cooperativa e seu sócio, de produzir um fato, ou seja, uma relação jurídica com um determinado sentido, ou seja, de cooperação, o que pressupõe para este fato uma ausência de interesses econômicos opostos. Enfim, uma relação jurídica de conteúdo econômico, mas sem oposição de interesses.

Dito isso, parece claro ser crível que decorra do ato cooperativo uma relação de consumo. Isso quer dizer que, se o sócio assume uma dupla qualidade na cooperativa - a de dono e a de usuário- e sua condição de consumidor se refere a determinadas manifestações desta última qualidade, que se manifestam com ambigüidade face à propriedade que ele exerce sobre a sociedade.

Em outras palavras, o que as cooperativas de consumo, eletrificação e habitacionais têm em comum é um certo modo pelo qual cumprem a finalidade delas: o aumento indireto de renda pelo sócio ${ }^{3}$. Toda cooperativa objetiva a geração de renda para seu sócio pelas próprias operações que realiza com ele (e não pela distribuição dos resultados patrimoniais que aufere das operações que realiza em proveito próprio). As cooperativas de usuários e de compras em comum buscam

3 As cooperativas em que os sócios lhes outorgam poderes de disposição de bens ou serviços pessoais buscam gerar um acréscimo de renda direto ao sócio. Ou seja, nas cooperativas de produtores, trabalhadores ou de vendas em comum, há uma busca do aumento do valor nominal da renda dos sócios. 
um aumento do poder aquisitivo dos sócios com o mesmo valor nominal de renda mantido pelos sócios. Sendo o objeto das transações bens de consumo, ou a elas equiparadas para fins de direito, se estabelece uma relação de consumo entre o sócio e a sua cooperativa. Mas nessa relação há um sentido de cooperação, que lhe é intrínseco e intencionalmente estabelecido mediante o ato cooperativo: a identidade do interesse tanto do sócio, como da cooperativa nas operações que realizam entre si -o aumento do valor real de renda daquele- .

Em que pese esse saber, o paradigma de relação de consumo originalmente dado, ao qual se impôs a defesa do consumidor, não incluía as manifestações que decorriam do ato cooperativo. O paradigma da relação de consumo sobre o qual se erigiu um sentido de justiça na defesa do consumidor se originou de uma pré-compreensão pela qual este se estabelecia a partir de atos de mercado.

Ninguém cogita a aplicação do Código de Defesa do Consumidor em favor do mendigo que recebe, ou a ele foi prometida, uma cesta básica fornecida por uma entidade assistencial. Ou mesmo face ao condomínio em função dos serviços que ela fornece aos seus condôminos, como a limpeza e a manutenção das áreas e equipamentos de uso comum. Mas muitos membros da magistratura, que não são ignorantes, nem insensíveis, têm cogitado a aplicação do Código de Defesa do Consumidor às relações de consumo, ainda que orientadas pela manifesta intenção de cooperação, quando nelas predomina um conteúdo econômico transacional, o que ocorre nas operações decorrentes de atos cooperativos. Qual a razão?

\section{A defesa do consumidor}

Embora o paradigma da defesa do consumidor seja a relação de consumo estabelecida com a oposição de interesses entre aquele e o fornecedor, ou seja, sua gênese é um ato de mercado - a compra e venda de bens ou serviços - não é esse o conceito fundante do sentido de justiça na defesa do consumidor. O conceito fundamental é o da assimetria na relação de consumo, com a conseqüente hipossuficiência do consumidor em relação ao fornecedor nas sociedades de consumo em massa.

A idéia da assimetria é tão fundamental ao senso de justiça contemporânea, que ela não somente é um conceito-chave do Direito Consumerista, mas também do Direito do Trabalho e do Direito Concorrencial. Reconhece-se sua manifestação até mesmo nas relações mais classicamente burguesas: não é novidade a existência de normas 
públicas de proteção de acionistas minoritários e de transparência na gestão das Sociedades Anônimas em relação a esses acionistas.

O processo histórico de concentração do capital e escalada da economia teve no cooperativismo uma resposta aos seus efeitos perversos, tanto como os direitos sociais também se apresentaram como uma resposta. A diferença essencial entre essas respostas é que a cooperativa originalmente não colocava em xeque as premissas de metajurídicas codificadas no séc. XIX: sua pretensão foi instaurar, pela cooperação racionalmente estabelecida pelos cidadãos, a utopia da igualdade das potências volitivas no mundo vivido da economia. Conquanto o conceito da assimetria significou uma revolução dos fatos sociais sobre os sujeitos ideais, livres, iguais e racionais do Direito de um Estado que se constituía como liberal e se transmudava em um Estado do bem estar social.

Essa diferença dificulta a composição dos direitos, na medida em que o Direito Cooperativo regula relações entre potências volitivas originariamente iguais, conquanto os Direitos consumerista, trabalhista e concorrencial originariamente regulam relações entre desiguais. Mas, a comunhão histórica de causa e de propósitos destes direitos não autoriza a afirmação de um pela negação do outro.

A questão é: ainda que as operações entre a cooperativa de consumo, eletrificação ou habitacional e seus respectivos sócios tragam em sua gênese o ato cooperativo, ou seja, a intenção manifesta de cooperarem, isso impede que se estabeleça uma relação fática assimétrica? O que os magistrados estão intuindo na sua experiência judicante é não. $\mathrm{E}$, entre não dar defesa ao consumidor cooperante, ou dar-lhe a única sistematizada no direito pátrio, o CDC, ainda que não exatamente adequado ao paradigma da cooperativa, muitos optam, num cálculo utilitarista, pela segunda hipótese.

\section{A assimetria nas cooperativas}

Os cooperativistas tendem à recusa em admitir a assimetria, porque o consumidor é dono da sociedade e deve manter vínculos de cooperação e solidariedade com os demais sócios, eis que esse é o sentido da affectio societatis na cooperativa. Por isso, não admitem que esse consumidor deva ser protegido em relação à sua sociedade, tanto quanto essa proteção demandada por um onere o conjunto de seus pares. A sua defesa portanto se confunde com o exercício da propriedade da sociedade, conforme as próprias relações societárias que se estabeleceram pela adesão à cooperativa, de modo a não fazer sentido falar em defesa da sua condição de consumidor. 
Porém, a questão consumerista, como revolução dos fatos, não se resolve a partir de soluções apriorísticas ideais. O que se intui da experiência originária do mundo vivido nas cooperativas é uma assimetria nas relações entre o sócio, como consumidor e a sua cooperativa, que se manifesta como um efeito colateral às portas abertas.

Desde cedo, os cooperativistas compreenderam que a affectio societatis nada tem a ver com grupamentos restritos de pessoas ${ }^{4}$.

Vejamos, por exemplo, que é que conseguiu no seu aspecto de empresa econômica conseguiu uma cooperativa [de consumo] de Hamburgo —a Produktion — fundada em 1899 com 700 associados, mas logo em 1918 passou a ter 80.000 e 130.000 em 1933.

$(\ldots)$

A cooperativa de Leeds, em Inglaterra, que não é ali a mais importante, tinha em 1946 nada menos do que 110.000 associados, o que representava já então mais de metade das famílias da cidade. O número das sucursais era nessa data de 240, constituídas por: 98 casas de comidas, 77 talhos, 19 lojas de fanqueiro, 16 carvoarias, 6 casas de artigos para homens e 5 vendas de peixe e legumes, fornecidos estes por suas granjas existentes nos arredores da cidade. ${ }^{5}$

Cumpre ressaltar ainda que o princípio das portas abertas é particularmente pertinente às cooperativas de consumo:

A formulação dos chamados 'princípios de Rochdale', apresentados à ACl, em 1934, no Congresso de Londres, inspirou-se visivelmente na organização das cooperativas de consumo ${ }^{6}$. (....) Não há como negar que o princípio da 'livre adesão' poderá ter aplicação irrestrita nas cooperativas de consumo; nem sempre, porém, a terá nas cooperativas de produção, com capacidade técnica limitada. Interpretando a «livre adesão» não em termos absolutos, mas relativos, já acentuava CUNZ que só assim seria ele extensivo às demais sociedades cooperativas. ${ }^{7}$

Compreende-se tal afirmativa na medida em que o princípio de portas abertas se expressa na abertura da cooperativa a todos aque-

${ }^{4}$ Afinal, o conceito surgiu para designar nada mais do que um elemento difuso na sustentação da pax romana em toda a sua extensão

5 Agudo: ob. cit., pp. 8-9.

61 - adesão livre; 2 - administração democrática; 3 - retorno na proporção das compras; 4 - juro limitado ao capital; 5 - Neutralidade política e religiosa; 6 - pagamento em dinheiro à vista; 7 - Fomento da educação cooperativista.

7 Franke: ob. cit., p. 70. 
les que desejem utilizar os serviços prestados pela sociedade. Ocorre que, nas sociedades de consumo, sejam elas de bens, serviços essenciais ou moradia, as pessoas físicas em geral assumem a condição de consumidoras e neste passo, se tornam aptas, a priori, a cooperarem.

Mas, na medida em que a condição de identidade societária se universaliza, evidentemente se dilui a affectio societatis. Toda afinidade se fixa não somente pela identidade dos sujeitos, mas também pelo que os difere dos sujeitos não vinculados. A partir deste contraste entre identidade/diversidade é que nasce a affectio societatis ${ }^{8}$.

Assim é que, nas cooperativas de consumo, a afirmação da affectio societatis passou comumente pela superposição da condição de consumidor com outra, de matriz estranha ao objeto próprio dessas sociedades. Surgiram assim as cooperativas de consumo fechadas. CHARLES GIDE, cuja produção intelectual é tida como um dos pilares da doutrina cooperativista, ainda em 1913 se debruçou sobre a questão, e sua manifestação influenciou a posição posterior do cooperativismo mundial a respeito das cooperativas de consumo:

«Sociedades cooperativas que somente admitem membros de uma mesma empresa ou profissão são bem numerosas. Assim, há sociedades dos empregados de ferrovias, suboficiais, trabalhadores e funcionários de uma mesma fábrica, por exemplo as sociedades de mineiros da Anzin ou de trabalhadores de Creusot etc.

"Sociedades Cooperativas reservadas a certas classes tem suas vantagens e suas desvantagens.

«A vantagem é que o espírito de solidariedade —o "espirit de corps" - é muito mais fortemente desenvolvido entre pessoas de mesma empresa que entre pessoas de ocupações várias.

«(....)O caráter de cooperação dos consumidores —o qual, sendo universal pela sua exata definição— não demanda de seus aderentes outra condição que a de ser consumidores. As cooperativas fechadas trazem divisões para o movimento cooperativista, enfraquecendo sua força.»

«(....)É melhor portanto evitar sociedades cooperativas de classes especiais tanto quanto possível, apesar de que em algumas circunstâncias, elas serão necessárias. $)^{9}$

8 Na Antiga Roma, a affectio societatis evidentemente era manifesto entre os patrícios, mas não entre os patrícios e os escravos. Estes se sujeitavam às leis e à ordem social romana pela subjugação militar.

9 Gide, Charles: Consurmers' Co-operative Societies. Manchester: Co-operative Union, 1921. 77-78. 
Portanto, para a doutrina cooperativista, é perfeitamente aceitável cooperativas de consumo abertas, que consagram em plenitude o princípio das portas abertas. Nestes casos, entretanto se impõe um intenso esforço de criação da afinidade e organização do quadro social, de forma a compensar, pela educação cooperativista, a diluição da affectio societatis entre os sócios consumidores.

O que outrora era uma opção, mais de caráter doutrinário do que prático, em que as cooperativas de consumo fechadas vicejaram pela maior facilidade de sua organização pelo corte corporativo, passou a ser uma imposição operacional de vida ou morte.

Poucas atividades tiveram seus custos tão impactados pelos ganhos de escala, como o comércio varejista de bens de consumo, ensejando o predomínio mundial de gigantes como a Wal Mart e Carrefour. Emblemático é o emprego do ECR-Efficient Consumer Response. Trata-se de um instrumento capital intensivo de relacionamento em rede entre empresas varejistas, distribuidoras e industriais viável somente em fluxos de produtos em larga escala - particularmente os de consumo- . O ECR impulsionou a concentração empresarial nos EUA ao proporcionar ali uma vantagem concorrencial para as operações de grande porte na ordem de 30 bilhões de dólares anuais em logística e redução dos estoques em torno de $41 \%$. Estes números causaram queda de até $10 \%$ do preço final dos produtos para o consumidor.

As cooperativas de consumo não estão imunes a esse processo histórico de concentração e ganho de escala:

«A única maneira de fazer frente aos problemas atuais de distribuição é a montagem de lojas em forma de supermercado, e se isso for possível, de hipermercado, de modo a que se possa efetuar o máximo de venda com um mínimo de pessoal assalariado.

Se calcula hoje (1980) na Espanha que um comércio de gêneros alimentícios (cooperativas incluídas) têm de vender um mínimo de quinze milhões de pesetas por ano por cada empregado que tenha. Se não se consegue essa cifra, do ponto de vista econômico, a cooperativa está fadada ao fracasso. A obtenção destas cifras supõe um profissionalismo que as cooperativas pequenas não podem ter. $\mathrm{E}$ por isso se torna imprescindível a fusão de todas as cooperativas para conseguir uma empresa capaz de pagar bons profissionais.

«Este caminho é o que foi empreendido pela grande maioria das cooperativas na Inglaterra, Suécia, França, Itália, Alemanha, etc. etc. (....) . Não havia outra alternativa que não crescer ou desaparecer». ${ }^{10}$

10 Colomer, Josep Castaño: La cooperativa de consumo. Barcelona: CEAC, 1982, p. 133. 
Na escala necessária para que a cooperativa de consumo se faça presente no mercado concentrado, ou seja, na modalidade super-hiper, isso é impossível sem a massificação de seu quadro social. Hoje (dez/2003), no Brasil, se as cooperativas de consumo respondem por menos de $2 \%$ total das cooperativas em funcionamento, seus cooperados correspondem a 33,32\% dos 5.762 .718 de brasileiros nesta condição.

As Cooperativas de consumo, outrora fechadas, hoje se abriram aos consumidores que delas queiram compor o quadro social. Tal abertura se deu por um imperativo de sobrevivência do cooperativismo em seu ramo pioneiro. E, de acordo com a doutrina cooperativista, como visto, embora tal fenômeno dilua a affectio societatis na cooperativa, a abertura e massificação, por si só, não autoriza a conclusão de seu desaparecimento por completo. Enfim, a massificação do quadro social, por si só, não desnatura a natureza cooperativa da sociedade.

A Secretaria de Direito Econômico, em parecer de lavra da Coordenadora Elisa SILVA RIBEIRO BAPTISTA DE OliveIRA, constante nos autos do processo administrativo 08000.018405/97-11, tendo como Representante a Associação Brasileira de Supermercados e como Representada a COOPERHODIA, soube perfeitamente compreender a manifestação da affectio societatis nas cooperativas de consumo de quadro social:

«Isso não quer dizer que as cooperativas devam ter características de pequeno negócio, já que transmitem idéia de simplicidade e despojamento, como entendimento manifestado pela Representada às fls. 617. Para que possam atingir os objetivos propostos, as cooperativas devem atuar e apresentar características próprias da atividade exercida.

«No caso em análise, ou seja, das cooperativas de consumo atuando no setor de supermercado, entende a Representante que o tamanho da cooperativa a esteja desviando dos objetivos sociais a que se propõe.

«Tal entendimento entretanto não possui fundamento legal. Pelas características do mercado onde atuam, é certo que o tamanho do negócio está diretamente ligado ao seu sucesso.

«Em face das grandes cadeias nacionais e internacionais instaladas no mercado de atuação da Representada, o poder de barganha junto aos fornecedores é fator indispensável para a sobrevivência em um mercado altamente competitivo.

(....)

«Do mesmo modo, a utilização de técnicas modernas de gerenciamento e marketing é perfeitamente compatível com o cooperativismo. Ao contrário do que muitas vezes se acredita, o cooperativismo deve ser estimulado, como dispõe a CF, para que seja realmente uma 
alternativa. O associado deve encontrar na cooperativa uma opção de preço, mas que ofereça o conforto, a variedade de produtos, enfim, outros benefícios oferecidos pelos demais supermercados.

(...)

«O crescimento das cooperativas, que podem apresentar-se como grandes complexos cooperativos multinacionais é apontado como natural (....)»

"Quanto à livre associação, ressalta-se que se trata de imperativo legal (Lei 5.764/71), sendo inclusive um dos princípios básicos do cooperativismo.»

Outrossim, as portas abertas diluem o poder decisório nas cooperativas, pois o poder per capita que se exerce nas cooperativas com poucos sócios resta distinto ao que se exerce nas sociedades de muitos. O exercício altera progressiva e radicalmente a natureza das relações de poder democrático, que tende a se cristalizar nas estruturas de mediação e gestão (ainda que consubstanciadas na personificação de uma liderança individual carismática) e nos jogos de hegemonia e contra hegemonia, e não na idealidade da potência volitiva manifesta em cada um dos muitos indivíduos decisores numa última instância, ainda que suprema.

E mais, as portas abertas, como visto, traz uma economia de escala para a cooperativa, quando as prioridades de sua realização não necessariamente pressupõem a urgência na satisfação do consumidor individualmente identificado em momento posterior ao ato transacional de fornecimento.

Da mesma forma, o monopólio natural dentro do polígono envolvente potencializa a assimetria na cooperativa de eletrificação, bem como a escala global de recursos envolvidos no empreendimento cooperativo, em contraste com a contribuição individual de cada sócio e a essencialidade dos objetos, com a conseqüente inelasticididade da demanda dos mesmos pelos sócios, ao mesmo leva às cooperativas, tanto as de eletrificação, como as habitacionais.

Em que pese as mutações reais que as portas abertas, as condições de realização da cooperação e a natureza dos objetos trazem à cooperativa na sua relação com o seu sócio, permanecem essencialmente as mesmas relações de consumo mantidas com ele, porque as necessidades do sócio individualmente considerado permanecem as mesmas. Sob o ponto de vista do sócio, a assimetria na sua relação, na ambigüidade de sua condição na cooperativa de consumo, eletrificação e habitacional - como dono e como consumidor - tende a preponderar, no plano fático, essa última. Pois, se a condição de sócio pressupõe o 
exercício de sua propriedade sobre a sociedade cooperativa, já originariamente limitada por sua natureza, as determinadas condições dadas a diluem.

\section{A transcendentalidade da relação da cooperativa com o seu sócio consumidor para sua adequada defesa}

Por tudo que foi dito até agora neste ensaio, resta afirmado que a condição de cooperante não desnatura a condição de consumidor. De um lado, a cooperação, como identidade de interesses econômicos entre a cooperativa e o sócio, torna a relação entre eles essencialmente distinta daquela que se verifica entre consumidores e fornecedores encontrados no mercado. Sendo este o paradigma das normas de defesa do consumidor até agora sistematizadas e codificadas, restam elas inadequadas, se aplicadas à cooperativa. Por outro lado, a assimetria na relação entre o sócio consumidor e sua cooperativa é uma manifestação que a cooperação atenua, mas não elimina.

Por isso, o senso de justiça contemporânea impõe, de alguma forma, a defesa do cooperante na sua condição universal de consumidor. E impõe-se o encontro de novos sentidos ao Direito Cooperativo e ao Direito Consumerista para encontrar um tratamento adequado ao ato cooperativo na defesa do consumidor.

Talvez um bom ponto de partida seja a velha lição de HANS KELSEN sobre o fenômeno da recepção constitucional de lei: se permanecem válidas em linguagem comum, são lei nova do ponto de vista jurídico. Não é a mesma lei, porque seu fundamento de validade é distinto. Quando se muda uma Constituição, não é apenas a Constituição que muda, mas todo o ordenamento ${ }^{11}$.

No primeiro tomo desta obra, há uma dedução de que a cooperação foi alçada à condição de valor constitucional. A cooperativa e o ato cooperativo são manifestações da cooperação na ordem econômica constitucional, o que dá sentido ao disposto nos arts. 5. ${ }^{\circ}$, XVIII, 146, III, C, $174, \S \S 2 .^{\circ}, 3^{\circ}{ }^{\circ}$ e $4 .^{\circ}, 186$ e 192 da Carta de Outubro. ROQUE CARRAZZA, em sua gentil apresentação daquele tomo, logrou sintetizar:

«(....)o Constituinte não só acreditou no cooperativismo, como determinou que esta peculiar forma associativista fosse, por todos os títulos, prestigiada pela ordem jurídica.

11 Teoria general del derecho y del Estado. México: UNAM, 1969, p. 138. 
Em resumo, o cooperativismo é um valor que, por seu particular significado político, social e econômico, foi consagrado, pela Assembléia Nacional Constituinte, em repetidas passagens da Constituição da República.

Conseqüentemente, tudo o que diga respeito às cooperativas deve receber uma interpretação generosa, posto ser vontade do Constituinte —explicitamente manifestada — incentivá-las (....)»

Partindo da premissa que a cooperativa e o ato cooperativo são manifestações da cooperação na ordem econômica, com base nos estudos de SIGISMUNDO BIALOSKORSKI ${ }^{12}$, pode-se deduzir três elementos fundamentais da cooperação, quando ali se manifesta:

- A democracia como valor intrínseco à atividade econômica.

- Geração de riqueza vinculada ao desenvolvimento local.

- Eficácia em ambientes de escassez de capital e em mercados imperfeitos.

Por isso, não é senso de justiça aceitável um tratamento inadequado ao ato cooperativo na defesa do consumidor, mesmo que o tratamento seja indicado por um cálculo utilitarista. Ainda que o CDC traga a única ordem sistemática de defesa do consumidor, não é lícito ignorar que o ato cooperativo manifesta um valor e um projeto de realização do bem comum que não foi originariamente levado em consideração pelo texto codificado, mas é reconhecido pela Constituição Federal como querido.

Por outro lado, se se assume que a cooperação é um valor constitucional, que se afirma na ordem econômica através do aparecer da cooperativa e da prática dos atos cooperativos, também há que se admitir, em razão disso, que o apoio e estímulo ao cooperativismo está "obrigado" a participar do jogo — concertado- de restrições e complementações recíprocas em que consiste o processo de concretização dos princípios e valores constitucionais» ${ }^{13}$. Nesse passo, há que se considerar que a defesa do consumidor é uma norma-princípio da constituição expresso no seu art. 170. Portanto, a «otimização» do ato cooperativo está condicionada, de fato e de direito, à concretização da defesa do consumidor.

Nesse passo, o ato cooperativo, conceito-chave do sistema operacional das cooperativas (arts. 79 e ss. da Lei 5.764/71), cujo ordena-

12 Aspectos econômicos das cooperativas. BH: Mandamentos, 2006.

13 Mendes: ob. cit., p. 1.297. 
mento foi recepcionado pela Constituição Federal ${ }^{14}$, tem em seu fundamento constitucional impacto do princípio de defesa do consumidor. Portanto, não é lícito que a cooperativa esteja fora de alcance das normas de defesa do consumidor em relação ao seu sócio, na condição de consumidor.

Como resolver o impasse?

A alternativa da cooperação na ordem econômica face à atividade exploratória que caracteriza a empresa, desoculta um sentido constitucional mais amplo à defesa ao consumidor que aquele estrito contido no texto codificado. Deste texto, sendo o único vigente, há que se extrair o conteúdo essencial no que se refere à boa-fé e a validação da manifestação da vontade, indicando qualidades para a relação de consumo que não podem ser ignoradas pela cooperativa e se incorporam compulsoriamente às suas prioridades e urgências, porque impostas por normas de ordem pública.

Para isso, há de se considerar que a defesa do consumidor é uma garantia individual e pessoal de seu sócio, cuja disponibilidade não está sujeita à supremacia assemblear, consequentemente à pura discricionariedade das regras regimentais da cooperativa. Entretanto, seu exercício é por ela condicionada de algum modo para se lograr um adequado tratamento ao ato cooperativo de consumo.

\section{A constituição de um adequado tratamento ao ato cooperativo de consumo}

Tudo isso induz à percepção de uma lacuna legislativa, eis que falta sistematizar um adequado tratamento ao ato cooperativo de consumo por normas públicas. Partem elas do pressuposto da menor hipossuficiência presumida do consumidor, quando sócio de uma cooperativa, em especial as de eletrificação e habitacionais. O CDC pode ser aplicado sistematicamente me defesa do sócio da cooperativa de consumo, como se exporá ao final.

A hipossuficiência está mitigada pela autogestão da cooperativa. Por isso, pertine ao marco legal faltante reconhecer os direitos universais do consumidor, mas delega às normas regimentais o modo de exercício destes direitos, pois a autogestão não é exatamente substância, mas essencialmente um modo.

14 cf. Mandados de Injunção 701-2/400-DF, 702-1/400-DF,703-9/400-DF, 
Se a cooperativa é um exercício da democracia, não interessa uma tutela pública que a degenere pelo paternalismo a frustar a manifestação da cooperação em sua plenitude na ordem econômica.

Poder-se-á suprir essa carência com termos de ajustamento de conduta firmados com o Ministério Público. Pois, da ponderação do valor da cooperação e o princípio de defesa do consumidor, é constitucionalmente exigível das cooperativas habitacionais e de eletrificação normas regimentais compatíveis com a principiologia consumerista, sem as quais, presumir-se-á o desvio de finalidade que justifica a aplicação do CDC face aos seus sócios.

Se a cooperativa possui, no âmbito do ato cooperativo, identidade de interesses com o seu sócio, interessa-Ihe que as expectativas deles sejam atendidas em nível equiparado ao exigível pelos demais consumidores na sociedade brasileira. A relação de consumo cooperada não pode ser de qualidade inferior ao padrão exigível das relações de consumo existentes no mercado.

A cooperativa de consumo, por sua vez, deve orientar-se para que a aplicação do CDC se faça face ao real fornecedor na relação de mercado havida, que não é ela, mas o terceiro cujo produto ou serviço a cooperativa capta no mercado para colocar a disposição do seu sócio. Pois, há que se considerar a atuação da cooperativa no mercado, por conta e ordem de seu sócio, ainda aja em nome próprio.

Caso a cooperativa não preveja as condições de garantia dessa adequada aplicação da legislação protetiva ao consumidor, então ela responderá nos termos do CDC, por se encontrar em desvio de sua finalidade, que é bem servir ao seu sócio.

Portanto, reitera-se: os sócios das cooperativas de consumo são sempre protegidos pelo CDC. E a cooperativa está orientada a buscar sua aplicação adequada ao ato cooperativo de consumo ao concorrer para a efetividade dessa proteção. 